\title{
Allozyme variation in Ulmus species from France: analysis of differentiation
}

\author{
NATHALIE MACHON* ${ }^{*}$, MADELEINE LEFRANC $\uparrow$, ISABELLE BILGER $\ddagger$, SUSAN J. \\ MAZER $† \S \&$ ABOUBAKRY SARR $\dagger$ \\ †Laboratoire d'Evolution et de Systématique des Végétaux, Batiment 362, Université Paris-Sud, F-91405 Orsay \\ Cedex and $\ddagger$ CEMAGREF, Domaine des Barres, F-45290 Nogent-sur-Vernisson, France and \$Department of Ecology, \\ Evolution and Marine Biology, University of California, Santa Barbara, CA, 93106, U.S.A.
}

In the present paper, the geographical structure of genetic variation in three French elm taxa is described using electrophoretic data. For three species, Ulmus laevis, U. glabra and U. minor, two kinds of analyses were performed. First, the genetic parameters (genetic diversity indices) of individuals sampled from naturally regenerating forest were compared to samples of cultivated ornamental trees. Secondly, when sample sizes were sufficient, the genetic parameters of trees sampled from different regions of France were compared to detect geographical differentiation. From these analyses, the ultimate aim was to offer recommendations concerning the conservation policies of the genetic resources of French elms. The heterozygosity of Ulmus $\times$ hollandica (the presumed hybrid between $U$. minor and $U$. glabra) was compared to its putative parent taxa to determine whether the hybrid harbours great levels of genetic variation. In spite of the ravaging effects of Dutch Elm disease in the past, all three species exhibit high levels of electrophoretic variation. The three species surveyed displayed similar levels of genetic diversity, proportions of polymorphic loci and levels of allelic diversity in trees harvested from naturally regenerated forests relative to cultivated ornamental trees. High levels of genetic diversity in $U$. minor within geographical regions of France were detected, with only moderate levels of genetic differentiation detected between regions. Ulmus $\times$ hollandica is not more heterozygous than either of its parent species, suggesting that extant representatives of this taxon are the result of past and ongoing backcrosses with the parental taxa. Ongoing efforts to preserve the genetic variation still present in French elms should take advantage of their high levels of electrophoretic variation and target genetically distinct, vegetatively reproducing genotypes in their natural environment.

Keywords: French elms, genetic diversity, geographical differentiation, hybrids, isozymes, Ulmus.

\section{Introduction}

The advantages of electrophoretic surveys of proteins as measures of genetic diversity are well known. These techniques are commonly used because they offer an efficient and cost-effective examination of many randomly sampled loci. They also play an important role in the quantitative evaluation and management of genetic resources because information concerning the geographical and taxonomic distribution of genetic variation provides guidelines for sampling strategies for germplasm preservation (Brown, 1978). Electrophoretic analyses

${ }^{*}$ Correspondence. E-mail: machon@psisun.u-psud.fr of species that have undergone severe bottlenecks may provide helpful guidelines for efforts to preserve the genetic variation they may still harbour. For example, electrophoretic surveys may be able to identify specific populations or geographical regions that should be targeted in order to sample remaining genetic variation. The degree to which the conservation of electrophoretic genetic variation results in the preservation of genetic variation that allows a species to tolerate or to adapt to future environmental change depends on a positive association between neutral and adaptive genetic variation.

Since 1970, Dutch Elm Disease has had a destructive impact on the rural and urban landscape of Europe. This ecological catastrophe has already affected most of the present-day adult Ulmus trees 
such that the survivors are primarily juvenile trees and shoots. In the face of this epidemic, the need for effective conservation measures was recognized in 1987. At this time, the French Institute of Agricultural and Environmental Engineering Research CEMAGREF was instructed by the French Ministry of Agriculture to carry out a programme to survey and to protect the genetic resources represented by elm species. Because no reliable data on the genetic variability of French elms existed, a systematic collection of vegetative material from natural populations and cultivated trees was undertaken to initiate a field gene bank located at Nogent-surVernisson (Loiret, France).

In a previous study, Machon et al. (1995) used isoenzymes to assess the genetic variability of the three French species of elms: Ulmus laevis Pall. from section Blepharocarpus, U. minor Mill. and U. glabra Huds. from section Ulmus. According to isozymic inheritance and diversity, three main conclusions were reached: (i) French elms behave like segmental tetraploids; (ii) $U$. laevis produces isozyme patterns which differentiate it from species in the section Ulmus; and (iii) there exists a high level of isozyme polymorphism within the French elm species. In the present paper, the geographical structure of French elms using samples from the gene bank collection at Nogent-sur-Vernisson and from trees in their natural habitat was investigated. Data from one isoenzyme system have been previously reported by Pearce \& Richens (1977) and Richens \& Pearce (1984) for European elms. In this paper, we report and discuss data from the same seven isoenzyme systems as in the previous study, from 351 elm trees (50 more than in the previous study).

For two of the three species studied (U. laevis and $U$. glabra), sample sizes were too small to permit a conclusive and quantitative investigation of the geographical differentiation among regions. The case of $U$. laevis is unusual because in France it is almost only found in forests from the east. Sampling elsewhere in the country was difficult. Ulmus glabra is more widespread in France but it was easier to harvest in the east because there the species is relatively easily distinguished morphologically. In contrast, in the plains regions of northern France and Normandy, it was often partially hybridized with $U$. minor. For these reasons, the geographical differentiation of these species was not thoroughly studied here. On the other hand, the decorative qualities of elm trees and their rapid growth made them ideal for lining streets or roads or for decorating parks and gardens. Thus, in France, two kinds of Ulmus glabra and $U$. laevis can be found: cultivated trees for ornamental purposes and natural trees growing in forests. Ulmus minor is rarely a forest tree; it is mostly found isolated or in hedgerows in plains and its management is more or less left to nature.

Three kinds of analyses were performed: (i) the genetic diversity indices of naturally regenerating forest-grown individuals were compared to cultivated ornamental trees; (ii) when sample sizes were sufficient (only in the case of $U$. minor), the genetic parameters of trees from different regions were compared to detect geographical differentiation; and (iii) the heterozygosity of the hybrid taxon $(U . \times$ hollandica) was compared to that of its putative parent species ( $U$. minor and $U$. glabra) to determine whether the hybrid harboured higher levels of genetic variation. The ultimate aim was to offer recommendations concerning conservation policies for the genetic resources of French elms.

\section{Materials and methods}

In accordance with the programme led by CEMAGREF, orientated towards the conservation of the genetic diversity of French elms, a thorough survey was carried out in five regions of northern France (Nord-Pas-de-Calais, Ile-de-France, Normandy, Poitou, eastern France) to record every mature and healthy elm tree (trunk diameter $>15 \mathrm{~cm}$ at height $>1.30 \mathrm{~m}$ ). In 1993, a field gene bank comprising a total of 270 trees was initiated from clonal shoots at Nogent-sur-Vernisson (Loiret, France). Given the small number of elm trees remaining in the studied regions after the epidemic of Dutch Elm Disease, classical sampling methods have not been used. Although our sampling method was not exhaustive, it seemed to be sufficient to estimate the genetic diversity of the elm species.

The plant material used for this study consisted of samples taken in 1993-94 from all the trees in the Nogent-sur-Vernisson plantation, in addition to other samples taken from trees in their natural environment. Overall, 351 trees were sampled. Using the Richens (1968) classification (based on morphological descriptors) the taxa and sample sizes represented are: Ulmus minor $(N=165$ trees); $U$. glabra $(N=52) ;$. laevis $(N=75)$; and 59 trees recorded as putative hybrids between $U$. minor and $U$. glabra (U. $\times$ hollandica Mill. sensu lato).

\section{Electrophoretic analyses}

For the enzyme extraction, young leaf tissue was crushed in liquid nitrogen using a mortar and pestle, 
and the enzymes extracted using a cysteine buffer: $1 \mathrm{~g}$ of leaf was ground with $3 \mathrm{~mL}$ of $10 \mathrm{~mm}$ Tris- $\mathrm{HCl}$ $\mathrm{pH}$ 7.2, $4 \mathrm{~mm}$ dithioerythritol, $5 \mathrm{~mm}$ cysteine and 10 per cent polyvinylpyrrolidone (soluble PVP). After centrifugation $\left(3000 \mathrm{~g}\right.$ for $20 \mathrm{~min}$ at $\left.4^{\circ} \mathrm{C}\right)$ extracts were stored at $-70^{\circ} \mathrm{C}$ until used for electrophoresis. Horizontal starch gels were composed of 13 per cent starch. Catalase (CAT; EC 1.11.1.6), anodic peroxidase (PRXA; EC 1.11.1.7) and phosphoglucoisomerase (PGI; EC 5.3.1.9) were resolved using a lithium-borate electrode and gel buffer adapted from Soltis \& Soltis (1990). Malate dehydrogenase (MDH; EC 1.1.1.37), phosphoglucomutase (PGM; EC 5.4.2.2) and 6-phosphogluconate dehydrogenase (6PGD; EC 1.1.1.44) were resolved using a histidine gel and electrode buffer adapted from Soltis \& Soltis (1990). Cathodic peroxidase (PRXC; EC 1.11.1.7) was resolved using a tris-malate gel and electrode buffer adapted from Shaw \& Prasad (1970).

\section{Measures of genetic diversity}

For each taxon, measures of allozyme diversity were estimated using the software BIosys-1 (Swofford \& Selander, 1989). Nei's genetic diversity index (Nei, 1973) was calculated using data from all loci and the equation: $H_{\mathrm{T}}=1-\Sigma p_{i}^{2}$, where $p_{i}$ is the frequency of the $i$ th allele. Nei's genetic distances (Nei, 1972) were calculated using only those enzyme systems whose behaviour was disomic. The percentage of polymorphic loci $(P)$ was calculated by dividing the number of polymorphic loci (threshold 5 per cent) by the total number of loci scored. The mean number of alleles per locus $(A)$ was calculated by dividing the total number of alleles scored by the total number of loci for the different species in each region. The effective number of alleles per locus $\left(A_{\mathrm{e}}\right)$ was calculated as $A_{\mathrm{e}}=1 /\left(1-H_{\mathrm{e}}\right)$ where $H_{\mathrm{e}}$ is the expected heterozygosity assuming Hardy-Weinberg equilibrium.

For each species, the differentiation between geographical regions was expressed using $F$-statistics (Wright, 1965): (i) $F_{\text {IS }}$, the fixation index of each region, was calculated for all the individuals of one region as $F_{\mathrm{IS}}=1-\left(H_{\mathrm{o}} / H_{\mathrm{e}}\right)$ where $H_{\mathrm{o}}$ is the mean observed heterozygosity for all disomic loci, $H_{\mathrm{e}}$ is the mean Hardy-Weinberg expected heterozygosity for all disomic loci, and $F_{\mathrm{IS}}$ is the mean fixation index of the entire species as sampled here; (ii) $F_{\text {IT }}$, the fixation index of the total population, is calculated for all the sampled individuals of each species as $F_{\mathrm{IT}}=1-\left(H_{\mathrm{o}} / H_{\mathrm{e}}\right)$ and (iii) $F_{\mathrm{ST}}$, a measure of the genetic differentiation between regions, is calculated from the equation

$$
\left(1-F_{\mathrm{IT}}\right)=\left(1-F_{\mathrm{IS}}\right)\left(1-F_{\mathrm{ST}}\right) \text {. }
$$

\section{Statistical analyses}

In order to detect differences between allelic frequencies in cultivated and natural tree populations, $\chi^{2}$-tests were performed. The same tests were used to detect differences in heterozygosity between the hybrid and its parental taxa. In the case of $U$. minor, UPGMA (Unweighted Pair Group Method with Arithmetic Averaging, Nei, 1972) cluster analyses were performed using three disomic loci (6PGD, $P G I$ and $P R X C$ ) to determine whether geographical regions were statistically distinguishable from one another.

\section{Results}

\section{Genetic diversity of each species}

(1) Ulmus laevis Ulmus laevis showed relatively high levels of genetic variation. Seventy-five trees were analysed and seven staining systems revealed nine loci (Table 1). Three of the loci were monomorphic in the species. The average number of alleles per locus was 1.89 and the mean effective number of alleles was 1.30 . The mean genetic diversity was $H_{\mathrm{T}}=0.231$, although this parameter varied greatly from one enzyme system to another $(\mathrm{SE}=0.230)$. Among the $75 \mathrm{U}$. laevis analysed, 56 were sampled from forests growing in north-eastern France and 19 from the other northern regions where they were cultivated trees used for ornamental purposes. Because U. laevis is rather rare, the sampling in the other four French regions was too sparse to allow a study of its broad geographical structure, although it was possible to compare forest trees to ornamental trees.

Considering the allelic frequencies and sample sizes, no significant differences were observed between wild and cultivated trees for seven of the nine systems studied (Table 2). A $\chi^{2}$-test indicated significant differences for the $M D H$ and $P G M f$ loci. Furthermore, there was one rare allele (PGMf-1) that was present in the cultivated tree sample but absent from the forest tree sample. Estimates of genetic diversity $\left(H_{\mathrm{T}}\right)$ were similar in forest and cultivated samples.

(2) Ulmus glabra Forty-five individual wild trees, representing forests of north-eastern France, and 
Table 1 Allelic frequencies and diversity estimates for Ulmus laevis

\begin{tabular}{lccc}
\hline & Forest trees & Cultivated trees & Total \\
Sample size & 56 & 19 & 65 \\
\hline Prxas-1 & 1.000 & 1.000 & 1.000 \\
$N$ & 56 & 19 & 65 \\
Prxaf-1 & 1.000 & 1.000 & 1.000 \\
$N$ & 56 & 19 & 65 \\
Mdh-1 & 0.630 & 0.250 & 0.592 \\
Mdh-2 & 0.370 & 0.750 & 0.408 \\
$N$ & 27 & 3 & 30 \\
Pgmf-1 & 0.000 & 0.014 & 0.004 \\
Pgmf-2 & 0.095 & 0.026 & 0.077 \\
Pgmf-3 & 0.459 & 0.631 & 0.503 \\
Pgmf-4 & 0.446 & 0.329 & 0.416 \\
$N$ & 55 & 19 & 74 \\
Pgms-1 & 0.411 & 0.500 & 0.438 \\
Pgms-2 & 0.589 & 0.500 & 0.562 \\
$N$ & 28 & 12 & 40 \\
6 pgd-1 & 0.932 & 0.944 & 0.934 \\
6 pgd-2 & 0.068 & 0.056 & 0.066 \\
$N$ & 44 & 9 & 53 \\
Pgi-1 & 0.873 & 0.765 & 0.847 \\
Pgi-2 & 0.127 & 0.235 & 0.153 \\
$N$ & 55 & 17 & 72 \\
Prxc-1 & 0.955 & 0.885 & 0.917 \\
Prxc-2 & 0.045 & 0.115 & 0.083 \\
$N$ & 11 & 13 & 24 \\
Cat-1 & 1.000 & 1.000 & 1.000 \\
$N$ & 42 & 3 & 45 \\
$P$ & 66.7 per cent & 66.7 per cent & 66.7 per cent \\
$A$ & 1.78 & 1.89 & 1.89 \\
$A_{\mathrm{e}}$ & 1.28 & 1.29 & 1.30 \\
$H_{\mathrm{T}}$ & $0.218(0.232)$ & $0.226(0.210)$ & $0.231(0.230)$ \\
\hline Stangra & & &
\end{tabular}

Standard errors are in parentheses.

seven cultivated trees from other parts of France were sampled. This sample includes only trees that were recognized as 'pure' Ulmus glabra; it does not include hybrids.

As a result of the small sample sizes, the general results obtained apply primarily to forest trees (Table 3). They are genetically diverse, $H_{\mathrm{T}}=0.373$, and highly polymorphic, with a large number of alleles per locus: $A=2.75$ and $A_{\mathrm{e}}=1.59$. The results vary markedly from one enzyme system to another. All of the enzyme systems showed a deficiency of heterozygotes. For some of them, the deficit was very high, particularly in the tetraploid systems. For example, for the $P R X A$ slow system, almost all individuals were homozygous, which theoretically should be a very rare event.

The calculations representing the seven cultivated trees from the other regions of France showed the same tendencies but the small sample size precluded a statistical analysis.

(3) Ulmus minor Ulmus minor exhibited very high levels of genetic variation (Table 4). All the loci studied were polymorphic. The mean genetic diversity for this species was $H_{\mathrm{T}}=0.342$. The mean number of alleles per locus and the effective allele number per locus were 3.00 and 1.52 , respectively.

Even though the sampling regime was not completely balanced, the number of individuals harvested from each region permitted a genetic analysis of the degree of geographical differentiation. An $F_{\text {ST }}$ estimate of 0.179 denotes a moderate level of differentiation between regions. $F_{\text {IS }}$ values varied widely across regions. In contrast, mean $F_{\text {IT }}$ and $F_{\text {IS }}$ values over all populations were 0.345 and 0.202 , respectively. This indicates that genetic varia- 
Table $2 \chi^{2}$-tests comparing allele frequencies between forest trees and cultivated trees in Ulmus laevis

\begin{tabular}{lcrl}
\hline Locus & d.f. & \multicolumn{1}{c}{$\chi^{2}$} & $P$ \\
\hline$M D H$ & 1 & 6.44 & 0.011 \\
$P G M F$ & 3 & 11.55 & 0.0091 \\
$P G M s$ & 1 & 1.09 & 0.2968 \\
$6 P G D$ & 1 & 0.12 & 0.7255 \\
$P G I$ & 1 & 2.34 & 0.1260 \\
$P R X C$ & 1 & 0.76 & 0.3824 \\
\hline
\end{tabular}

PRXAs, PRXAf and CAT were not included because they were monomorphic in $U$. laevis.

tion within regions accounts for most of the genetic diversity in Ulmus minor.

Northern populations presented the highest genetic diversity and Normandy populations the lowest. Similarly, the highest mean number of alleles per locus was found in the north whereas the lowest was found in Ile-de-France.

UPGMA cluster analysis (Fig. 1) was performed using only three diploid loci (data for catalase systems were missing). This analysis revealed that different regions were genetically very similar to each other. The calculations of Nei's genetic distances showed a very low level of differentiation; trees from north-western France (Poitou or Normandy) were very similar to those from the eastern ones.

(4) Ulmus $\times$ hollandica The individuals considered as Ulmus $\times$ hollandica were supposed to be hybrids between $U$. minor and U. glabra. Forty-four trees came from Normandy and 15 from the rest of France. Genetic diversity has been reported previously (Machon et al., 1995) and geographical differentiation cannot be quantified because of the restricted sample size. In the current study, the observed heterozygosity of the hybrids was compared with that of the parental species (Table 5).

For some of the systems (PRXAs and $P G M$ ), observed heterozygosity seems to be higher for the hybrid than for the other species but the differences are not significant. For other systems (PRXAf, 6PGD and $P G I), H_{\mathrm{o}}$ of the hybrid is intermediate between those of the parental species (Fig. 2). Finally, heterozygosity is low compared to that of the parental species for $M D H, P R X C$ and $C A T$. On average, over all the enzyme systems, the differences between the hybrid and its putative parent species are not significant. It is therefore not possible to conclude that hybrid individuals differ in the level of heterozygosity from $U$. minor or U. glabra.

\section{Discussion \\ Genetic differences between naturally regenerating and cultivated trees}

Although the small sample sizes precluded the statistical analysis of geographical differentiation in $U$. laevis and $U$. glabra, all three species were sampled sufficiently to compare trees harvested in naturally regenerated forests with ornamental trees intentionally planted in villages, along roads or in parks. Among all types of trees, we detected similar levels of genetic diversity, proportions of polymorphic loci and levels of allelic diversity. A few minor differences were observed in allelic frequencies for some of the enzyme systems, but at the isozyme level forest and cultivated trees were genetically very similar to one another.

We suggest that regenerated and cultivated trees are genetically similar because the latter are probably directly propagated from natural populations. The lack of genetic differentiation between the two types of trees may result from the following: (i) the germination rate of elms is very low ( 1 or 2 per cent) and it is uncommon to allow cultivated elms to regenerate naturally; (ii) no breeding programmes have been carried out on elms; and (iii) the natural generation time is long. Propagation has almost certainly occurred only through vegetative propagation from the original forest trees.

\section{Geographical differentiation in Ulmus minor}

The high level of diversity within each population of $U$. minor and the moderate differentiation between them is noteworthy. This result is similar to those generally obtained for temperate forest tree species (Hamrick et al., 1992; Kremer, 1994). The main difference between our study and others is that we defined a 'population' to consist of trees coming from the same geographical region. We did so because natural, sexually reproducing populations do not exist for elm trees and therefore a 'population' cannot be defined in the usual way. Indeed, successful sexual reproduction is a very rare phenomenon among elms. In hedgerows, elms are vegetatively reproducing, and in parks or gardens or along roads, management is completely anthropogenic. In order to study geographical patterns of interpopulation differentiation in this species, we grouped sampled individuals by region. 
Table 3 Allelic frequencies and diversity estimates for Ulmus glabra

\begin{tabular}{|c|c|c|c|}
\hline Sample size & $\begin{array}{l}\text { Forest trees } \\
\qquad 45\end{array}$ & $\begin{array}{c}\text { Cultivated trees } \\
7\end{array}$ & $\begin{array}{c}\text { Total } \\
52\end{array}$ \\
\hline Prxas-1 & 0.098 & 0.042 & 0.086 \\
\hline Prxas-2 & 0.674 & 0.500 & 0.638 \\
\hline Prxas-3 & 0.206 & 0.458 & 0.258 \\
\hline Prxas-4 & 0.022 & 0.000 & 0.018 \\
\hline$N$ & 23 & 6 & 29 \\
\hline Prxaf-1 & 0.061 & 0.042 & 0.059 \\
\hline Prxaf-2 & 0.389 & 0.416 & 0.392 \\
\hline Prxaf-3 & 0.339 & 0.500 & 0.358 \\
\hline Prxaf-4 & 0.211 & 0.042 & 0.191 \\
\hline$N$ & 45 & 6 & 51 \\
\hline$M d h-1$ & 0.575 & 0.400 & 0.550 \\
\hline$M d h-2$ & 0.425 & 0.600 & 0.450 \\
\hline$N$ & 30 & 5 & 35 \\
\hline Pgmf-1 & 0.110 & 0.071 & 0.104 \\
\hline Pgmf-2 & 0.146 & 0.143 & 0.146 \\
\hline$P g m f-3$ & 0.201 & 0.107 & 0.187 \\
\hline Pgmf-4 & 0.543 & 0.679 & 0.563 \\
\hline$N$ & 41 & 7 & 48 \\
\hline $6 p g d-1$ & 0.953 & 1.000 & 0.958 \\
\hline 6 pgd-2 & 0.047 & 0.000 & 0.042 \\
\hline$N$ & 32 & 4 & 36 \\
\hline Pgi-1 & 0.045 & 0.167 & 0.060 \\
\hline Pgi-2 & 0.955 & 0.666 & 0.920 \\
\hline Pgi-3 & 0.000 & 0.167 & 0.020 \\
\hline$N$ & 44 & 6 & 50 \\
\hline Prxc-1 & 0.083 & 0.357 & 0.160 \\
\hline Prxc-2 & 0.917 & 0.643 & 0.840 \\
\hline$N$ & 18 & 7 & 25 \\
\hline Cat-1 & 0.769 & 1.000 & 0.786 \\
\hline Cat-2 & 0.231 & 0.000 & 0.214 \\
\hline$N$ & 26 & 2 & 28 \\
\hline$P$ & 100 per cent & 75 per cent & 100 per cent \\
\hline$A$ & 2.75 & 2.5 & 2.875 \\
\hline$A_{e}$ & 1.59 & 1.62 & 1.65 \\
\hline$H_{\mathrm{T}}$ & $0.373(0.240)$ & $0.382(0.238)$ & $0.393(0.218)$ \\
\hline
\end{tabular}

Standard errors are in parentheses.

Given the high frequency of vegetative reproduction, it would not have been surprising to detect genetic differentiation between trees sampled from distant regions in $U$. minor. However, our results suggest the contrary; we detected high levels of genetic similarity among trees harvested from different regions. Because sexual reproduction is nearly absent, long-distance pollen flow by itself probably does not explain this low differentiation between populations. We suggest that the long generation time of this species and its anthropogenic vegetative propagation may account for this pattern. In any case, the potential for postdisease population bottlenecks or genetic drift to create geographical differentiation in neutral allozymes does not appear to have been realized in this species.

\section{Genetic disposition of the hybrid U. $\times$ hollandica}

The results concerning the heterozygosity of $U . \times$ hollandica are in agreement with the hypothesis previously proposed by Machon et al. (1995). Given the morphological continuum between $U$. glabra and $U$. minor, in addition to the isozymic variation expressed by these species, there is strong evidence that a genetic continuum exists between $U$. glabra 
Table 4 Allelic frequencies, diversity and population genetic structure estimates for Ulmus minor

\begin{tabular}{|c|c|c|c|c|c|c|}
\hline Sample size & $\begin{array}{c}\text { North } \\
28\end{array}$ & $\begin{array}{c}\text { Norm } \\
43\end{array}$ & $\begin{array}{c}\text { East } \\
19\end{array}$ & $\begin{array}{l}\text { Poitou } \\
58\end{array}$ & $\begin{array}{c}\text { Ile de Fr } \\
17\end{array}$ & $\begin{array}{c}\text { Total } \\
165\end{array}$ \\
\hline Prxas-1 & 0.070 & 0.012 & 0.000 & 0.088 & 0.000 & 0.048 \\
\hline Prxas-2 & 0.190 & 0.154 & 0.033 & 0.060 & 0.077 & 0.106 \\
\hline Prxas-3 & 0.500 & 0.776 & 0.784 & 0.667 & 0.885 & 0.699 \\
\hline Prxas-4 & 0.240 & 0.058 & 0.183 & 0.185 & 0.038 & 0.147 \\
\hline$N$ & 25 & 39 & 15 & 54 & 13 & 146 \\
\hline Prxaf-1 & 0.045 & 0.000 & 0.000 & 0.000 & 0.000 & 0.009 \\
\hline Prxaf-2 & 0.455 & 0.543 & 0.412 & 0.486 & 0.589 & 0.477 \\
\hline Prxaf-3 & 0.446 & 0.457 & 0.559 & 0.559 & 0.411 & 0.498 \\
\hline Prxaf-4 & 0.054 & 0.000 & 0.029 & 0.005 & 0.000 & 0.016 \\
\hline$N$ & 28 & 35 & 17 & 51 & 14 & 145 \\
\hline$M d h-1$ & 0.750 & 0.333 & 0.536 & 0.118 & 0.438 & 0.291 \\
\hline$M d h-2$ & 0.250 & 0.667 & 0.464 & 0.882 & 0.562 & 0.709 \\
\hline$N$ & 4 & 36 & 14 & 53 & 16 & 123 \\
\hline Pgmf-1 & 0.109 & 0.038 & 0.078 & 0.066 & 0.094 & 0.070 \\
\hline Pgmf-2 & 0.500 & 0.359 & 0.500 & 0.478 & 0.500 & 0.455 \\
\hline Pgmf-3 & 0.337 & 0.519 & 0.391 & 0.456 & 0.406 & 0.442 \\
\hline Pgmf-4 & 0.054 & 0.084 & 0.031 & 0.000 & 0.000 & 0.033 \\
\hline$N$ & 23 & 39 & 16 & 57 & 16 & 151 \\
\hline $6 p g d-1$ & 0.833 & 0.903 & 0.917 & 0.900 & 0.864 & 0.894 \\
\hline $6 p g d-2$ & 0.167 & 0.097 & 0.083 & 0.087 & 0.136 & 0.101 \\
\hline $6 p g d-3$ & 0.000 & 0.000 & 0.000 & 0.013 & 0.000 & 0.005 \\
\hline$N$ & 6 & 36 & 6 & 40 & 11 & 99 \\
\hline Pgi-1 & 0.222 & 0.066 & 0.139 & 0.069 & 0.200 & 0.117 \\
\hline Pgi-2 & 0.741 & 0.908 & 0.861 & 0.892 & 0.800 & 0.856 \\
\hline Pgi-3 & 0.037 & 0.026 & 0.000 & 0.039 & 0.000 & 0.027 \\
\hline$N$ & 27 & 38 & 18 & 51 & 15 & 149 \\
\hline Prxc-1 & 0.000 & 0.000 & 0.071 & 0.071 & 0.143 & 0.052 \\
\hline Prxc-2 & 1.000 & 1.000 & 0.929 & 0.929 & 0.857 & 0.948 \\
\hline$N$ & 11 & 38 & 14 & 56 & 14 & 133 \\
\hline Cat-1 & - & 0.895 & 1.000 & 0.839 & 1.000 & 0.888 \\
\hline Cat-2 & - & 0.105 & 0.000 & 0.161 & 0.000 & 0.112 \\
\hline$N$ & - & 19 & 4 & 28 & 7 & 58 \\
\hline$P$ & 85.7 & 87.5 & 87.5 & 100 & 87.5 & 100 \\
\hline$A$ & 2.86 & 2.5 & 2.25 & 2.75 & 2.12 & 3.00 \\
\hline$A_{\mathrm{e}}$ & 1.71 & 1.44 & 1.45 & 1.47 & 0.47 & 1.52 \\
\hline$H_{\mathrm{T}}$ & 0.416 & 0.305 & 0.310 & 0.319 & 0.320 & 0.342 \\
\hline & $(0.231)$ & $(0.202)$ & $(0.212)$ & $(0.172)$ & $(0.189)$ & $(0.180)$ \\
\hline$F_{\mathrm{IS}}{ }^{*}$ & \multirow{2}{*}{\multicolumn{6}{|c|}{0.345}} \\
\hline $\begin{array}{l}F_{\mathrm{IT}}{ }^{*} \\
F_{\mathrm{ST}^{*}}\end{array}$ & & & & & & \\
\hline
\end{tabular}

Standard errors are in parentheses. 'North' is Nord-Pas-de-Calais, 'Norm' is Normandy, 'East' is eastern France, and 'Ile de Fr' is Ile-de-France

${ }^{*}$ Calculated only for diploid systems: 6PGD, PGI and PRXC. 


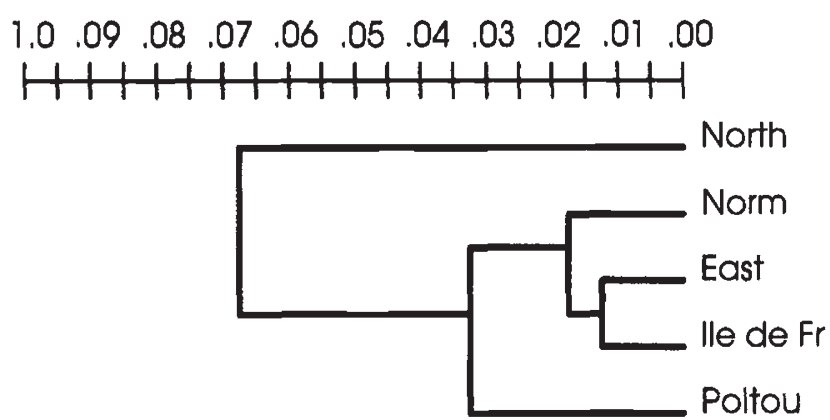

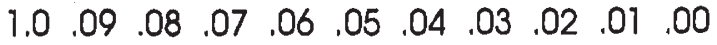

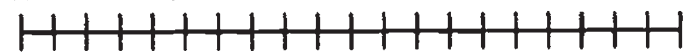

Nel's genetlc distances

Fig. 1 Cluster analysis using the unweighted pair group method of Nei's genetic distance of five French populations of Ulmus minor. 'North' is Nord-Pas-de-Calais, 'Norm' is Normandy, 'East' is eastern France and 'Ile de Fr' is Ile-de-France.

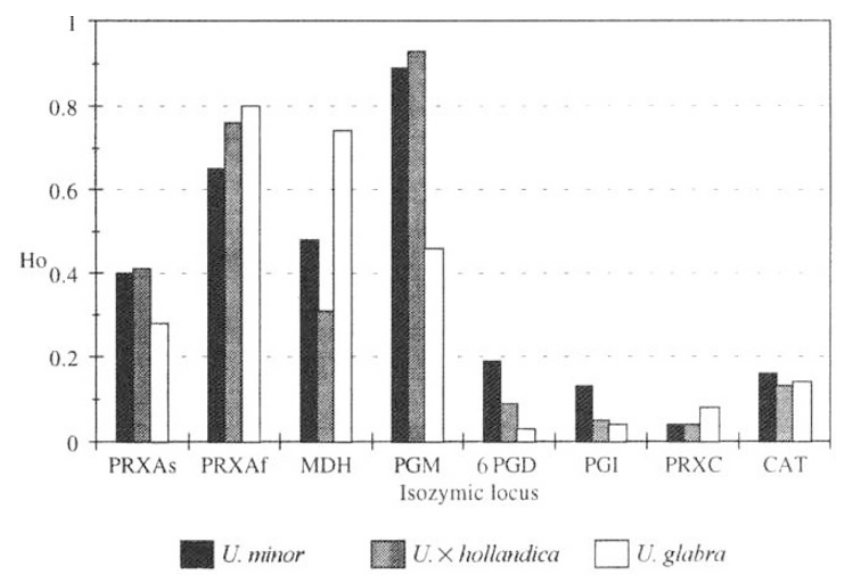

Fig. 2 Observed heterozygosity for Ulmus minor, U. glabra and their putative hybrid $U$. $\times$ hollandica for each electrophoretic system.

Table 5 Sample sizes and observed heterozygosities for Ulmus minor, U. glabra and their hybrids $U . \times$ hollandica

\begin{tabular}{|c|c|c|c|c|c|c|}
\hline & \multicolumn{2}{|c|}{$U$. minor } & \multicolumn{2}{|c|}{ U. $\times$ hollandica } & \multicolumn{2}{|c|}{ U. glabra } \\
\hline & $N$ & $H_{\mathrm{o}}$ & $N$ & $H_{\mathrm{o}}$ & $N$ & $H_{\mathrm{o}}$ \\
\hline$P R X A s$ & 146 & 0.40 & 51 & 0.41 & 29 & 0.28 \\
\hline$P R X A f$ & 145 & 0.65 & 53 & 0.76 & 51 & 0.80 \\
\hline$M D H$ & 123 & 0.48 & 48 & 0.31 & 35 & 0.74 \\
\hline$P G M$ & 151 & 0.89 & 54 & 0.93 & 48 & 0.46 \\
\hline $6 P G D$ & 99 & 0.19 & 48 & 0.09 & 36 & 0.03 \\
\hline$P G I$ & 149 & 0.13 & 53 & 0.05 & 50 & 0.04 \\
\hline$P R X C$ & 133 & 0.04 & 47 & 0.04 & 25 & 0.08 \\
\hline$C A T$ & 58 & 0.16 & 30 & 0.13 & 28 & 0.14 \\
\hline
\end{tabular}

and $U$. minor. The fact that $U . \times$ hollandica is not more heterozygous than individuals from the parental species strongly suggests that this taxon is composed of backcrosses with its parent species. Ulmus minor, $U . \times$ hollandica and $U$. glabra may thus be considered to be a large genetic pool without clear distinction among these taxa.

\section{Conclusions}

It is notable that these species, devastated by Dutch Elm disease, still possess high genetic variation, even higher than the level of genetic variation in other tree species (Hamrick et al., 1992). The neutral loci we studied do not seem to have been eroded by the effects of the disease, but we have no loci from clear reference populations of elms with which to compare them. Theoretically, a severe bottleneck causes a decline in genetic diversity (Nei et al., 1975), but in the case of elm trees the drift that follows a reduction in population size apparently has not occurred. In fact, the amount of diversity in extant populations is high, apparently similar to the level of diversity in the predisease populations.

It is important to note that this analysis of differentiation in Ulmus species was investigated with only one type of data: allozyme markers. The differentiation we detected probably does not coincide with other types of characters such as adaptive traits because natural selection can cause the strong development of population divergence in such traits (Eriksson et al., 1993). Usually, however, differentiation is more difficult to detect using isozyme genotypes than with metric trait measurements or other 
quantitative data (Lewontin, 1984). In order to define the best strategies for the management of genetic resources, it would be best to have both types of data available.

Nevertheless, the results obtained provide a guide for the continued maintenance and augmentation of the Ulmus conservatory plantation. For all biological resources, a commonly accepted goal is to maximize the genetic variation represented in the collection. The optimum strategy for further Ulmus collections may be to take large samples from field sites that represent as broad a range of environments as possible. In this manner, genotypic sampling is likely to capture a significant portion of the existing adaptive variation (Schoen \& Brown, 1993). Isozyme markers such as the ones described here may be profitably used to choose the size of the samples in each locality and to avoid the repeated sampling of identical genotypes within regions. Given that genetic diversity in these elm species is rather high, but differentiation among regions is low, the most efficient strategy for sampling the genetic variation harboured by these species may be to sample the same number of trees in each region while aiming also to sample genotypes with rare alleles. As no one region of northern France seems to harbour particularly high levels of electrophoretic variation, this sampling strategy may suffice to generate a relatively complete representation of the genetic resource provided by elms and to contribute to its long-term preservation.

\section{References}

BRown, A. H. D. 1978. Isozymes, plant population genetic structure and genetic conservation. Theor. Appl. Genet., 52, 145-157.

ERIKSSON, G., NAMKOONG, G. AND ROBERDS, J. H. 1993. Dynamic gene conservation for uncertain futures. Forest Ecol. Management, 62, 15-37.
HAMRICK, J. L., GODT, M. J. W. AND SHERMAN-BROYLES, S. L. 1992. Factors influencing levels of genetic diversity in woody plant species. New Forests, 6, 95-124.

KREMER, A. 1994. Diversité génétique et variabilité des caractères phénotypiques chez les arbres forestiers. Génet. Sél. Évol, 26, suppl. 1, 105-123.

LEWONTIN, R. C. 1984. Detecting population differences in quantitative characters as opposed to gene frequencies. Am. Nat., 123, 115-124.

MACHON, N., LEFRANC, M., BILGER, I. AND HENRI, J.-P. 1995. Isoenzymes as an aid to clarify the taxonomy of French elms. Heredity, 74, 39-47.

NEI, M. 1972. Genetic distance between populations. Am. Nat., 106, 282-292.

NEI, M. 1973. Analysis of gene diversity in subdivided populations. Proc. Natl. Acad. Sci. U.S.A., 70 , 3321-3323.

NEI, M., MARUYAMA, T. AND CHAKRABORTY, R. 1975. The bottleneck effect and genetic variability in populations. Evolution, 29, 1-10.

PEARCE, N. J. AND RICHENS, R. H. 1977. Peroxidase isozymes in some elms (Ulmus L.) of eastern England. Watsonia, 11, 382-383.

RICHENS, R. H. 1968. The correct designation of the European field elm. Feddes Repertorium, 79, 1-2.

RICHENS, R. H. AND PEARCE, N. J. 1984. Isoperoxidases variation in Ulmus L. Forestry, 57, 75-84.

SCHOEN, D. J. AND BROWN, A. H. D. 1993. Conservation of allelic richness in wild crop relatives is aided by assessment of genetic markers. Proc. Natl. Acad. Sci. U.S.A., 90, 10623-10627.

SHAW, C. R. AND PRASAD, R. 1970. Starch gel electrophoresis of enzymes. A compilation of recipes. Biochem. Genet. , 4, 297-320.

SOLTIS, D. E. AND SolTIS, P. S. 1990. Isozymes in Plant Biology. Chapman \& Hall, London.

SWOFFORD, D. AND SELANDER, R. 1989. BIOSYS-1: a FORTRAN program for the comprehensive analysis of electrophoretic data in population genetics and systematics. J. Hered., 72, 281-283.

WRIGHT, s. 1965 . The interpretation of population structure by F-statistics with special regard to systems of mating. Evolution, 19, 395-420. 